\title{
Assessment on Two-way PBL in Investment Risk Management Course
}

\author{
Hui Zuo \\ School of Economics and \\ Commerce \\ Guangzhou Economic Research \\ Institute of Innovation and \\ Transformation \\ Guangdong University of \\ Technology \\ Guangzhou City, China \\ zuohui_ne@163.com
}

\author{
Luxia Yi \\ School of Economics and \\ Commerce \\ Guangdong University of \\ Technology \\ Guangzhou City, China \\ cilu5@163.com
}

\author{
Danxiang Ai \\ School of Management \\ Guangdong University of \\ Technology \\ Guangzhou City, China \\ aidx78@gmail.com
}

\begin{abstract}
PBL teaching assessment indicator system is established in the paper and is used to evaluate the two-way PBL teaching effects on undergraduates in investment major. Through analysis of variance, we make comparison with oneway PBL teaching effects. Results indicate that two-way PBL in investment major is significantly effective than one-way PBL. Advantage of two-way PBL is to improve the teaching effects of PBL significantly and teaching methods partially. However, on the optimization of teaching contents, one-way is less different from two-way PBL. Teaching contents and methods improvements benefit from more participation of teachers and students, more reasonable role setting as well as more receptivity.
\end{abstract} effect

Keywords- Two-way PBL; investment major; undergraduate;

\section{INTRODUCTION}

Interaction is important in teaching for its better performance in training logical and creative thinking ability for students in the situation of objective and subjective dualmode communication. It will activate and expedite the students' mental activity, which is helpful for students to respond in real time to questions from teachers and also enlighten the students to question the teacher on highly related topics [1]. This kind of communication will improve the intelligence of both students and teachers [2]. Both tutors and learners will benefit from heuristic teaching. Knowledge is more accessible with more opportunity to form mental network and internal relations and can be easily transformed into innovative potential and action [3].

PBL with interaction is helpful for students to improve their abilities of discovering and solving problems. According to discovery learning theory, PBL with interaction is a mental process from discovery to investigation and finally to solution. First, the instructor explains related theories and makes analysis on them and the students interrogate in the learning [4]. Second, the instructor creates an environment of inspiring questions and answers [5]. The students need to seek the answers to prescribed or emerging questions. The difficult level of answering must be propitious to their learning and knowledge. Third, hypothesis will be made and students need to investigate all possibilities in the solutions [6]. Finally, hypothesis will be accepted or rejected after discussion and analysis [7].

Currently, some investment major have experienced PBL in the courses and achieved satisfactory effects [8-10]. However, in most of situations, only one-way PBL is experienced and assessed the effects of. In the process of one-way PBL, students have less incentive to question the design of environment and case and teacher has less opportunity to reconsider the questions from students and modify the design. Therefore, we introduce two-way PBL in investment major and try to assess its effects.

\section{EXPERIMENT DESIGN}

\section{A. Students and Groups}

We select two classes of investment major of Guangdong University of Technology. There 90 students altogether in the classes. From statistic summary, we find that there is no significant difference among them in age, gender and entry score distribution. Then, we divide them into two major groups (45 students in each group) and further divide each major group into four subgroups (11-12 students in each group). Two instructors will select four subgroups stochastically in eight subgroups for BPL teaching.

\section{B. Assessment Indicator System}

We select a detailed case in investment risk management course and use BPL in order to construct indicator system. We design standard questionnaire for survey when finish the case. According to the result of survey, we make confidence and validity test so as to complete the assessment indicator system.

1) Questionnaire design and survey

We develop the work of Marann ${ }^{[11]}$ in order to fit indicators to assess undergraduate of investment major in PBL. After redesign the weights of all the indicators, we include three first level indicators and 18 second level indicators in our assessment system (Tab. I). Base on the system, we design closed questionnaire and contain all of 18 indicators in it. The questionnaire will direct forward thinking and guide the students to answer all of the questions 
regularly in 12 minutes or so. The answer of each question are 5 isometric choices from completely agree (score 5) to completely disagree (score 1). Total score is the sum of all 40 questions. In the questionnaire, we also set 3 groups of logical related question in order to ensure the validity of the answer. If no less than two groups in logical related questions are answered contradictorily, the questionnaire will be dropped. Before the survey, we give a brief introduction of the method and the purpose of the experiment. The students will answer the questionnaire anonymously so as to improve the validity. We ask the course teacher to skirt around when issuing the questionnaire and collect all of the questionnaires as soon as the survey complete.

TABLE I. ASSESSMENT INDICATOR SYSTEM

\begin{tabular}{|c|c|c|c|c|c|}
\hline Content & Weight & Process & Weight & Effect & Weight \\
\hline Substantiality & 0.067 & Enthusiasm & 0.064 & $\begin{array}{c}\text { New } \\
\text { knowledge }\end{array}$ & 0.063 \\
\hline Advancement & 0.020 & $\begin{array}{c}\text { Good Role } \\
\text { playing of } \\
\text { Stu }\end{array}$ & 0.042 & $\begin{array}{c}\text { Practical } \\
\text { Skills }\end{array}$ & 0.057 \\
\hline Correlation & 0.042 & $\begin{array}{c}\text { Good Role } \\
\text { playing of } \\
\text { Tea }\end{array}$ & 0.042 & $\begin{array}{c}\text { Ability } \\
\text { Training }\end{array}$ & 0.065 \\
\hline Arrangement & 0.050 & logic & 0.060 & $\begin{array}{c}\text { Mental } \\
\text { Training }\end{array}$ & 0.060 \\
\hline Difficulty & 0.065 & Instrument & 0.059 & Cooperation & 0.066 \\
\hline Practicability & 0.064 & Liveliness & 0.051 & Fitness & 0.063 \\
\hline
\end{tabular}

2) Confidence Test

Inner correlation coefficient is targeted to test reinvestigate confidence of the questionnaire, Cronbach $\alpha$ coefficient is to test inner validity and Kendall W coefficient is to test the confidence of answerers. In Inner correlation test, we survey the students three times after PBL discussion. In each survey, totally there are 90 piece of questionnaire are issued and collected, in which there are 84,85 and 85 are considered valid respectively. Validity rate of three surveys are $93.33 \%, 94.44 \%$ and $94.44 \%$ respectively. The Inner correlation coefficients of all the survey is above 0.75 , which can be regarded as significant confidence for inner correlation in questionnaire. According to the result of answerer's confidence test, Kendall W is 0.822 significantly and indicates that most of answerers respond to the survey confidently. As to Cronbach $\alpha$ test, the coefficients of 3 first level indicators and the whole questionnaire are 0.857, 0.849, 0.891 and 0.877 respectively, which implies that the survey is inner valid significantly.

\section{3) Validity Test}

Exploratory Factor Analysis is used to test the structure validity of the indicator system. By factor analysis method and maximum variance orthogonal rotation, we develop three common factors. They can represent all of three first level indicators perfectly for that accumulated contribution of the factors can reach $79.72 \%$, which implies that the results of factor analysis is in conformity with the questionnaire structure. In order to test the dependence of the validity results, we make confirmatory factor analysis based on the alternative sample of the identical student groups and the results show the goodness of fit and structural validity are all acceptable (X2/df: 1.502, RMSEA: 0.025, NNFI: 0.92, CFI: 0.91).

\section{PBL Arrangements}

We select investment risk management as PBL course. The content covers risk identification, risks quantification, risk response and risk monitoring and control. One group takes one-way PBL as control group and the other take two way PBL as experiment group. PBL details are as follows:

\section{1) Questioning}

First, we identify and name the risks. We ask the teachers use a combination of brainstorming and reviewing of standard risk lists. There are different sorts of risks and teachers need to decide on a project by project basis what to do about each type. Second, risk need to be quantified in two dimensions. The impact and the probability of the occurring risk need to be assessed by the students. Third, there are four things students can do about a risk. The strategies for choose are:

- Avoid the risk. Do something to remove it. Use another supplier for example.

- Transfer the risk. Make someone else responsible. Perhaps a Vendor can be made responsible for a particularly risky part of the project.

- Mitigate the risk. Take actions to lessen the impact or chance of the risk occurring. If the risk relates to availability of resources, draw up an agreement and get sign-off for the resource to be available.

- Accept the risk. The risk might be so small the effort to do anything is not worthwhile.

At last, the teachers will ask students to continually monitor risks to identify any change in the status, or if they turn into an issue. It is best to hold regular risk reviews to identify actions outstanding, risk probability and impact, remove risks that have passed, and identify new risks.

2) $P B L$ discussion

We take a typical PBL in which students may elect a leader, time keeper and/or secretary for each PBL-session. The roles may rotate for each session. Flip charts, whiteboards or cards may be used during sessions to collect and structure items. The difference between the control group and the experiment group is that teacher will allow the students modify their original discussion design and respond to the students question immediately in the circumstance of the latter. PBL sessions are organized according to the Maastricht seven-step procedure.

- Step 1. Identify and clarify unfamiliar terms presented in the scenario.

- Step 2. Define the problem or problems to be discussed.

- Step 3. Aspects on basis of prior knowledge are collected.

- Step 4. Review steps 2 and 3 and arrange explanations into tentative solutions.

- Step 5. Formulating learning objectives; group reaches consensus on the learning objectives; tutor ensures learning objectives are focused, achievable, comprehensive, and appropriate. 
- $\quad$ Step 6. Self-independent learning; during this phase students are going home and study.

- Step 7. Group shares results of private study.

- $\quad$ Step 8. Feedback

When finish the whole process, we issue the questionnaires to all the students for surveying.

\section{THE RESULTS}

We survey all of the students by designed questionnaires in the same investigation and assessment way when finish the course. Totally there are 540 copies of question sheets are issued in three times of surveys, in which there are 507 copies $(93.88 \%)$ are valid. We carry out t test, $F$ test and Kruskal-Wallis $\chi 2$ test in order to tell the differences between the experiment group and the control group. The first two are parameter test for differences in means and variances and the last one is non-parameter test for differences in distribution.

The results show that the experiment group has better performance than the control group significantly (Tab. II and Tab. III). First, in the two-way PBL group, all of the three first level indicators are improved which implies that the students regard that two-way PBL is better than one-way PBL in content, process and effect. Weighted all indicators mean in two-way PBL is 4.343 , rising by $15.63 \%$ compared with in one-way PBL. All of 3 first level indicators and 18 second level indicators are improving significantly, which implies that two-way PBL is more advantageous and effective than one-way PBL. And, effect improvement $(28.71 \%)$ is more than process $(11.01 \%)$ and content improvement (6.04\%) apparently.

TABLE II. VARIANCE ANALYSIS

\begin{tabular}{|c|c|c|c|c|}
\hline \multirow{2}{*}{ Indicators } & \multicolumn{2}{|c|}{ Mean } & \multicolumn{2}{c|}{ Std. Dev. } \\
\cline { 2 - 5 } & OWPBL & TWPBL & OWPBL & TWPBL \\
\hline Substantiality & 3.996 & 4.098 & 0.726 & 0.724 \\
\hline Advancement & 4.063 & 4.059 & 0.699 & 0.236 \\
\hline Correlation & 4.059 & 4.059 & 0.713 & 0.252 \\
\hline Arrangement & 3.545 & 4.555 & 0.499 & 0.498 \\
\hline Difficulty & 3.957 & 4.091 & 0.757 & 0.288 \\
\hline Practicability & 3.988 & 4.106 & 0.726 & 0.309 \\
\hline Enthusiasm & 4.071 & 4.059 & 0.715 & 0.749 \\
\hline Role of Stu & 3.565 & 4.539 & 0.497 & 0.507 \\
\hline Role of Tea & 3.534 & 4.547 & 0.500 & 0.507 \\
\hline logic & 4.083 & 4.098 & 0.738 & 0.311 \\
\hline Instrument & 4.047 & 4.114 & 0.733 & 0.721 \\
\hline Liveliness & 3.605 & 4.535 & 0.490 & 0.508 \\
\hline New knowledge & 3.545 & 4.567 & 0.499 & 0.496 \\
\hline Practical Skills & 3.561 & 4.555 & 0.557 & 0.498 \\
\hline Ability Training & 3.553 & 4.535 & 0.498 & 0.500 \\
\hline Mental Training & 3.482 & 4.524 & 0.501 & 0.508 \\
\hline Cooperation & 3.502 & 4.531 & 0.501 & 0.500 \\
\hline Fitness & 3.545 & 4.547 & 0.499 & 0.499 \\
\hline Content & 1.209 & 1.282 & 0.095 & 0.059 \\
\hline Process & 1.226 & 1.361 & 0.086 & 0.081 \\
\hline Effect & 1.320 & 1.699 & 0.074 & 0.078 \\
\hline Weighted all & 3.756 & 4.343 & 0.151 & 0.138 \\
\hline
\end{tabular}

TABLE III. SIGNIFICANCE TEST

\begin{tabular}{|c|c|c|c|}
\hline Indicators & $\mathbf{t}$ & $\mathbf{F}$ & $\boldsymbol{\chi}^{2}$ \\
\hline Substantiality & $-1.589^{\triangle}$ & $1.007^{\triangle}$ & $2.161^{\triangle}$ \\
\hline Advancement & $0.090^{\triangle}$ & 8.748 & $0.107^{\triangle}$ \\
\hline Correlation & $0.005^{\triangle}$ & 7.982 & $0.067^{\triangle}$ \\
\hline Arrangement & -22.806 & $1.004^{\triangle}$ & 217.666 \\
\hline Difficulty & -2.632 & 6.937 & $4.273^{\triangle}$ \\
\hline Practicability & -2.382 & 5.532 & $3.046^{\triangle}$ \\
\hline Enthusiasm & $0.186^{\triangle}$ & $0.909^{\triangle}$ & $0.020^{\triangle}$ \\
\hline Role of Stu & -21.847 & $0.959^{\triangle}$ & 206.654 \\
\hline Role of Tea & $-0.306^{\triangle}$ & 5.616 & $0.020^{\triangle}$ \\
\hline logic & $-1.033^{\triangle}$ & $1.032^{\triangle}$ & $0.899^{\triangle}$ \\
\hline Instrument & -21.007 & $0.931^{\triangle}$ & 195.369 \\
\hline Liveliness & -23.106 & $1.010^{\triangle}$ & 221.385 \\
\hline New knowledge & -21.169 & $1.253^{\triangle}$ & 203.762 \\
\hline Practical Skills & -22.160 & $0.994^{\triangle}$ & 209.462 \\
\hline Ability Training & -23.241 & $0.970^{\triangle}$ & 223.981 \\
\hline Mental Training & -23.159 & $1.004^{\triangle}$ & 221.990 \\
\hline Cooperation & -22.610 & $1.001^{\triangle}$ & 215.204 \\
\hline Fitness & -10.412 & 2.531 & 93.053 \\
\hline Content & -18.077 & $1.123^{\triangle}$ & 213.934 \\
\hline Process & -55.599 & $0.887^{\triangle}$ & 379.028 \\
\hline Effect & -45.434 & $1.190^{\triangle}$ & 374.473 \\
\hline Weighted all & -45.434 & $1.190^{\triangle}$ & 374.473 \\
\hline
\end{tabular}

Furthermore, we find that improvement differs among second level indicators (Tab. IV). We divide all of the second level indicators by two dimensions. One is variance difference and the other is mean difference. The former indicates the validity of improvement and the latter indicates the significance of improvement. It is found that 9 indicators show valid and significant improvement of two-way PBL and 3 indicator shows that less valid while still significant improvement of two-way PBL. Therefore, 12 indicators show that two-way PBL is significantly improving altogether.

TABLE IV. INDICATOR STRUCTURE

\begin{tabular}{|c|c|c|}
\hline & Equal Mean & Different Mean \\
\hline & & Arrangement \\
& & Role of Stu \\
& & Instrument \\
& Substantiality & Liveliness \\
Eomoscedasticity & Enthusiasm & New knowledge \\
& logic & Practical Skills \\
& & Ability Training \\
& & Mental Training \\
& & Cooperation \\
\hline \multirow{3}{*}{ Heteroscedasticity } & Advancement, & Difficulty \\
& Correlation, & Practicability \\
& Role of Tea & Fitness \\
\hline
\end{tabular}

As to teaching effects, we find that in all of valid and significant improving indicators, 5 items are of effects and only 1 is of content. It implies that students are more sensitive to the improvement of teaching effects than to the improvement of teaching content. Due to interaction and feedback in the process of BPL, the course will bring more freshness to the students and improve their initiative.

As to teaching contents, only one out of 18 second level indicators is valid and significant, which implies that the students disagree the differences between two-way PBL and 
one-way PBL. The main reasons lie in that the discrepancies between one-way PBL and two-way PBL is guide and implement mode rather than contents. Teachers in different groups use the similar questions and the "ideal" answer will seldom change with the guide and implement mode. Thus, students can hardly tell the difference in teaching contents. Furthermore, we find indicators concerned with contents are heteroscedasitic, which suggests that the responds of the students are less valid to teaching contents than effects. Therefore, we regard that two-way $\mathrm{PBL}$ is not more advantageous than one-way PBL.

As to teaching process, half of the indicators are improved significantly while the remaining half are regarded unchanged. The most convictive argument is that students can launch emergency mode in two-way PBL, which not only allow the pre-designed project to be modified in the procedure, but also ask the teachers to respond to unexpected real time questions. Thus, there is further participation in two-way PBL than one-way PBL and the students will have a good opinion of the teaching.

\section{CONCLUSIONS}

According to the statistic results and analysis, we conclude that two-way PBL is more advantageous than traditional one-way PBL in investment major courses. Teaching effects are improved significantly in two-way PBL while teaching contents are seldom changed in the new mode. The change of teaching effect and teaching process benefits from more interaction, participation and better role playing, which will promote the student's understandings.

We also conclude that two-way PBL can help the teacher find the student's interest and question rapidly as well as to reconsider the whole arrangement of teaching. Two-way PBL is helpful to form a lively and enquiring mind of both teachers and students. The questions from students and the responds from teachers stimulate each other and launch a new cycle of questioning and answering. New questions may be produced in the process of solution, which will offer more experiences to both teachers and students than traditional one-way PBL. After productive discussion, new knowledge can be easily mastered by students and surly affect their potentials. Furthermore, two-way PBL encourage the students to express their ideas and create good characters for both students and tutors. Finally, we want to emphasize that full preparation is strongly suggested in two-way PBL due to its complexity. The teacher should illustrate the two-way PBL at the beginning and ask the students make full preparation for it. A backup program is recommended in order to deal with emergencies, e.g. the students replace the pre-designed project by a completely new one.

\section{ACKNOWLEDGEMENT}

This work was financially supported by the National Social Science Foundation of China (11CTQ020), the National Natural Science Foundation of China (71203037), the Foundation for Distinguished Young Talents in Higher Education of Guangdong (2012WYM-0049) and Key Educational Project of Guangdong University of Technology (20102010).

\section{REFERENCES}

[1] Sharmila Torke, Reem Rachel Abraham, K Ramnarayan, et al. Peer Guided Cooperative Learning Enhances the Performance of Refresher Students. Advanced Physiological Education, 2007. (31): pp.118-124.

[2] C Barron, V Lambert, J Conlon, et al. The Childs, World: a Creative and Visual Trigger to Stimulate Student Enquiry in a Problem Based Learning Module. Nurse Education Today, 2008. 28(7): pp.962-969.

[3] Suzanne Novak, Sonalee Shah, P James, et al. Pharmacy Students Learning Styles Before and after a Problem - based Learning Experience. American Journal of Pharmaceutical Education, 2006. 70(4): pp. 74.

[4] Kiguli-Malwadde, E., et al., 1453: Learning Ultrasound in the Problem-Based Learning (PBL) Curriculum at Makerere University. Ultrasound in Medicine \& Biology, 2009. 35(8, Supplement): pp. S222.

[5] Choon-Eng Gwee, M., Globalization of Problem-based Learning (PBL): Cross-cultural Implications. The Kaohsiung Journal of Medical Sciences, 2008. 24(3, Supplement): pp. S14-S22.

[6] Duncan, M.J., M. Smith and K. Cook, Implementing online problem based learning (PBL) in postgraduates new to both online learning and PBL: An example from strength and conditioning. Journal of Hospitality, Leisure, Sport \& Tourism Education, 2013. 12(1): pp. 7984.

[7] Yeh, Y., Integrating collaborative PBL with blended learning to explore preservice teachers' development of online learning communities. Teaching and Teacher Education, 2010. 26(8): pp. 1630-1640.

[8] Alkhasawneh, I.M., et al., Problem-based learning (PBL): Assessing students' learning preferences using vark. Nurse Education Today, 2008. 28(5): pp. 572-579.

[9] Achike, F.I. and N. Nain, Promoting problem-based learning (PBL) in nursing education: A Malaysian experience. Nurse Education in Practice, 2005. 5(5): pp. 302-311.

[10] Manning, C.K., WebCT discussions in problem based learning (PBL): analysis of use by representative groups in an introductory food science course. Journal of the American Dietetic Association, 2004. 104, Supplement 2(0): pp. 40

[11] B Marann, F Babara. Assessing the Teaching Quality of Accounting Programmes: an Evaluation of the Course Experience Questionnaire [J]. Assess Evaluation High Education, 2003. 28(2): pp.135-145. 